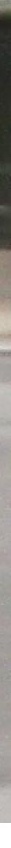

\section{NIOSH Research Demonstrates the Effectiveness of No-Nose Bicycle Seats in Reducing Groin Pressure and Improving Sexual Health}

About 40,000 workers in public safety occupations ride bicycles as part of their job including police officers, security staff, and emergency medical providers. Research has shown that workers who ride as part of their job may be at risk for genital numbness or more serious sexual and reproductive health problems as a result of pressure in the groin area from the traditional (nosed) bicycle seat. These traditional seats have been associated with urogenital paresthesia (i.e., tingling, itching, burning) and sexual dysfunction in bicycle patrol police officers. In recent years, the National Institute for Occupational Safety and Health (NIOSH) has conducted several research studies demonstrating the effectiveness of no-nose bicycle seats in reducing pressure to the groin and improving the sexual health of male bicycle patrol police officers. A no-nose bicycle seat does not have any material that protrudes between the thighs of the cyclist, and is designed to reduce or eliminate compression of the nerves and arteries located forward of the bones on which the cyclist sits. A traditional seat has a narrow nose that protrudes
- Police officers going to an International Police Mountain Bike Association (IPMBA) meeting. Photo by Brian Lowe

\section{Relevant Information}

\subsection{0-5.37 pounds per square inch}

(psi) $=$ pressure in the groin area while cycling on a traditional bicycle seat. $2.32 \mathrm{psi}=$ pressure of an arm blood pressure cuff needed to restrict blood flow in the arteries.

$1.02 \mathrm{psi}=$ pressure in the groin area while cycling on a no-nose bicycle seat. Bicycle patrol police officers spend approximately 25 hours per week sitting on a bicycle seat while on duty.

Recent evidence suggests that nonose bicycle saddles may also benefit women's sexual health.

\section{$f(3)$}

Follow NIOSH on Facebook and Twitter Sign up for eNews at cdc.gov/niosh/enews 
under the groin as the cyclist straddles the bicycle that supports part of the person's weight where the groin contacts the seat's nose, which can compress the nerves and arteries.

In one study, NIOsH provided no-nose seats to bicycle patrol officers from 5 metropoli$\tan$ areas to use over a 6 month period. Results showed a marked reduction in pressure to the groin by at least $65 \%$ and significant improvements in penis tactile sensation and erectile function. The percentage of men who reported not experiencing urogenital paresthesia while using the no-nose seat for a period of 6 months rose from $27 \%$ to $82 \%$. Ninety-percent of bicycle officers who tried the no-nose seat were still using it 6 months later. In addition, one participating police department ordered 400 no-nose seats following the study. NIOsH recommends that workers who ride a bicycle as part of their job take the following steps to help prevent sexual and reproductive health problems.

\section{NIOSH Recommendations}

Use a no-nose seat for workplace bicycling. It may feel very different so allow time to adjust to riding with the new seat. No-nose seats may not always be available at retail bicycle shops but are readily available for purchase through the internet.

Seek guidance on proper fit from a trained bicycle fit specialist. Use of a no-nose seat may require different height and angle adjustments. Make sure the seat is adjusted according to the manufacturer's instructions.

Dismount the bicycle when at a standstill. Do not lean against a post or other object in order to stay seated when you are not riding.

Dismount the bicycle if you begin to have numbness, tingling, or loss of feeling in any part of your body. These are warning signs that should not be ignored. Contrary to what some cyclists believe, it is not normal for any body part to go numb or lose feeling.

Visit www.cdc.gov/niosh for more information about research efforts to protect the safety and health of bicycle patrol officers (NIOSH publication number 2009-131). Authors of Cutting Off the Nose to Save the Penis-Steven Schrader, Michael Breitenstein, and Brian Lowe; Division of Applied Research and Technology; NIOSH_received the 2009 Alice Hamilton Award in the Human Studies category.

\section{SAFER • HEALTHIER P PEOPLE ${ }^{T M}$}

U.S. Department of Health and Human Services

Centers for Disease Control and Prevention

National Institute for Occupational Safety and Health

To receive $\mathrm{NIOSH}$ documents or more information about occupational safety and health topics, please contact $\mathrm{NIOSH}$. Telephone: 1-800-cdc-info (1-800-232-4636) | TTY: 1-888-232-6348 | email: cdcinfo@cdc.gov | www.cdc.gov/niosh For a monthly update on news at $\mathrm{NIOSH}$, subscribe to $\mathrm{NIOSH}$ eNews by visiting www.cdc.gov/niosh/eNews. DHHS (NIOSH) Publication No. 2010-163
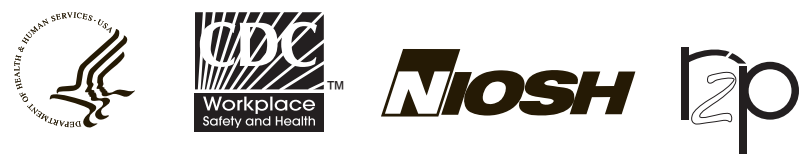